\title{
Benthic communities at two remote Pacific coral reefs: effects of reef habitat, depth, and wave energy gradients on spatial patterns
}

Kingman Reef and Palmyra Atoll in the central Pacific are among the most remote coral reefs on the planet. Here we describe spatial patterns in their benthic communities across reef habitats and depths, and consider these in the context of oceanographic gradients. Benthic communities at both locations were dominated by calcifying organisms ( 54 - 86 percent cover), namely hard corals ( 20 - 74\%) and crustose coralline algae (CCA) (10 - 36\%). While turf algae were relatively common at both locations $(8-22 \%)$, larger fleshy macroalgae were virtually absent at Kingman $(<1 \%)$ and rare at Palmyra $(0.7$ - 9.3\%). Hard coral cover was higher, but with low diversity, in more sheltered habitats such as Palmyra's backreef and Kingman's patch reefs. Almost exclusive dominance by slow-growing Porites on Kingman’s patch reefs provides indirect evidence of competitive exclusion, probably late in a successional sequence. In contrast, the more exposed forereef habitats at both Kingman and Palmyra had higher coral diversity and were characterized by fast-growing corals (e.g., Acropora and Pocillopora), indicative of more dynamic environments. In general at both locations, soft coral cover increased with depth, likely reflecting increasingly efficient heterotrophic abilities. CCA and fleshy macroalgae cover decreased with depth, likely due to reduced light. Cover of other calcified macroalgae, predominantly Halimeda, increased with depth. This likely reflects the ability of many calcifying macroalgae to efficiently harvest light at deeper depths, in combination with an increased nutrient supply from upwelling promoting growth. At Palmyra, patterns of hard coral cover with depth were inconsistent, but cover peaked at mid-depths at Kingman. On Kingman’s forereef, benthic community composition was strongly related to wave energy, with hard coral cover decreasing and becoming more spatially clustered with increased wave energy, likely as a result of physical damage leading to patches of coral in localized shelter. In contrast, the cover of turf algae at Kingman was positively related to wave energy, reflecting their ability to rapidly colonize newly available space. No significant patterns with wave energy were observed on Palmyra's forereef, suggesting that a more detailed model is required to study biophysical coupling there. Kingman, Palmyra, and other remote oceanic reefs provide interesting case studies to explore biophysical influences on benthic ecology and 
dynamics.

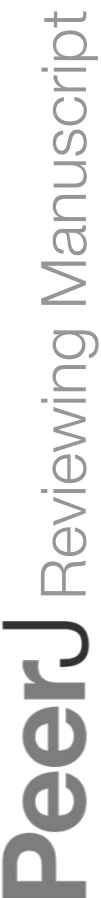

PeerJ reviewing PDF | (v2013:04:416:1:0:NEW 8 May 2013) 
1 G. J. Williams ${ }^{1 \S^{*}}$, J. E. Smith ${ }^{1 \S}$, E. J. Conklin², J. M. Gove ${ }^{3}$, E. Sala ${ }^{4,5}$, S. A. Sandin ${ }^{1}$

2

$3{ }^{1}$ Center for Marine Biodiversity and Conservation, Scripps Institution of Oceanography, La Jolla, 4 CA 92083, USA.

$5 \quad$ 2The Nature Conservancy, 923 Nuuanu Avenue, Honolulu, HI 96817, USA.

$6{ }^{3}$ Coral Reef Ecosystem Division (CRED), Pacific Islands Fisheries Science Center (PIFSC),

7 NOAA, 1610 Kapiolani Blvd., Suite 1110, Honolulu, HI 96814, USA.

$8{ }^{4}$ Centre d’Estudis Avançats de Blanes, Consejo Superior de Investigaciones Científicas, 17300

9 Blanes, Spain.

$10 \quad{ }^{5}$ National Geographic Society, Washington, DC 20036, USA.

11

$12{ }^{*}$ corresponding author, EMAIL: gareth@ucsd.edu, TEL: 858-534-8783, FAX: 858-822-1267

13 §authors contributed equally to this work

14

15

16

17

18 
20 On many coral reefs, combinations of natural and anthropogenic forcings interact to influence

21 benthic dynamics (Grigg 1995). For example, nutrient pollution can fuel algal growth and

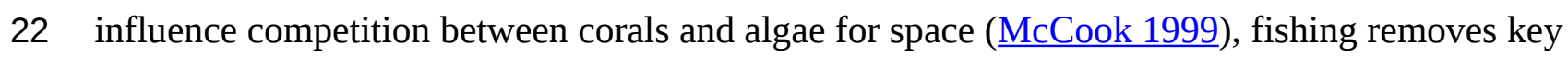

23 fish species, such as herbivores, that maintain algal standing stocks (Jackson et al. 2001), and

24 coastal development increases sedimentation, leading to smothering and death of corals

25 (Fabricius 2005). While natural forcings are still present (ughes and Connell 1999), their

26 relative influence on benthic community dynamics on a given reef may vary depending on the

27 magnitude of anthropogenic disturbances (Barott et al. 2012). These interactions make it

28 challenging to discern the independent effects of human-induced versus natural forcings on coral

29 reef dynamics and community organization.

30 Throughout the Pacific Ocean there are numerous remote islands and atolls (Maragos and

31 Williams 2011). These remote reefs lack local human impacts and are often characterized by

32 high fish biomass (Williams et al. 2011c) and benthic communities dominated by hard corals and

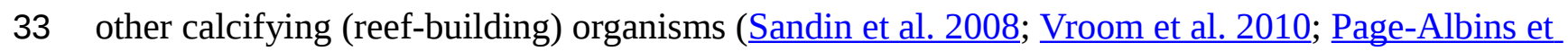

34 al. 2012). In the absence of local human impacts, intra-island variation in reef community

35 organization is likely a result of natural variations in predation, competition for space, gradients

36 in physical forcings such as light and wave energy, and disturbance events, such as storms

37 (Hughes 1989; Rogers 1993; Hughes and Connell 1999). For example, the decrease in irradiance

38 with depth is a crucial factor limiting the distribution of autotrophic organisms such as algae

39 (Huston 1985). The distribution of scleractinian (stony) corals is also structured by depth, but the

40 patterns are often more complex (Done 1983). Like algae, corals receive most of their energy

41 from photosynthesis via their symbiotic zooxanthellae (Muscatine and Porter 1977), though most 
42 colonies, particularly zooxanthellate soft corals, actively supplement themselves through

43 heterotrophy (Fabricius and Dommisse 2000). Thus, corals have more trophic flexibility than

44 algae and are less constrained in their depth distributions. Particulate food supply often increases

45 with depth (i.e., with increased proximity to sources of upwelling), creating a nutrient and

46 energy-rich environment for coral growth (Leichter and Salvatore 2006). However, high

47 oscillatory flow in the shallows may also supply a high flux of particulate food and nutrients

48 (Sebens and Johnson 1991).

49 Other physical forcings, such as wave energy gradients, also play a major role in species

50 zonation and benthic community organization on coral reefs (Bradbury and Young 1981; Done

51 1983; Dollar and Tribble 1993). Extreme wave energy in shallow waters may reduce overall

52 coral cover and favor communities dominated by more wave-tolerant growth forms with greater

53 structural integrity (Dollar 1982; Madin and Connolly 2006). These communities may remain

54 characterized by early colonizers, as repeated disturbances prevent the establishment of a

55 late-successional climax community (Grigg 1983; Hughes and Connell 1999). Because algae are

56 also vulnerable to physical dislodgement (Engelen et al. 2005), these communities may also shift

57 to more wave-tolerant species and morphologies, such as encrusting and turf algae, with

58 increased wave energy.

59 Kingman Reef and Palmyra Atoll, approximately $1300 \mathrm{~km}$ south of Hawaii in the northern Line

60 Islands, central Pacific, are among the most remote coral reefs on the planet. These reefs

61 represent a biodiversity hotspot in the central Pacific (Maragos and Williams 2011), and previous

62 expeditions have documented their high fish biomass and live coral cover (Sandin et al. 2008;

63 Friedlander et al. 2010; Kenyon et al. 2010) and diverse algal assemblages (Tsuda et al. 2012).

64 Kingman and Palmyra have been protected as National Wildlife Refuges by the U.S. Fish and 
65 Wildlife Service since 2000 and 2001, respectively. In 2009, both became part of the Pacific

66 Remote Islands Marine National Monument, further reinforcing their high-level conservation

67 status (Kenyon et al. 2012). Here, we use Kingman and Palmyra as case studies to shed light on

68 the natural history of benthic community patterns on remote oceanic reefs in the Pacific. Our aim

69 was to provide a comprehensive description of benthic community patterns across reef habitats,

70 depths and, in particular, across horizontal wave energy gradients.

71 We first compare and contrast benthic communities between more sheltered and environmentally

72 stable reef habitats, to those habitats more exposed to open ocean conditions and therefore

73 punctuated disturbance events, such as large swells. Secondly, we examine benthic community

74 shifts in response to increases in depth; specifically, whether relationships exist between depth

75 and: 1) the cover of macroalgae (e.g., decrease in cover with increases in depth following

76 reduced light availability), 2) the cover of hard coral (e.g., peak at intermediate depths where

77 there is a balance between food availability and levels of physical disturbance), and 3) the cover

78 of soft corals (e.g., increase in cover with depth due to increasingly efficient heterotrophic

79 abilities). Lastly, we examine how horizontal gradients in wave energy influence various aspects

80 of benthic community organization; specifically, whether relationships exist between wave

81 energy and: 1) hard coral cover (e.g., decrease in cover with increasing wave energy), 2) spatial

82 clustering of corals (e.g., higher clustering with increasing wave energy due to selection for more

83 wave-tolerant species in pockets of localized shelter), 3) algal cover (e.g., generally more or less

84 algae present in areas of higher wave energy), and 4) algal community structure (e.g., more

85 wave-tolerant morphologies with increasing wave energy).

86 


\section{Materials and methods}

88 Study sites

89 Data were collected at Kingman Reef National Wildlife Refuge (NWR) $\left(6.4^{\circ} \mathrm{N}, 162.4^{\circ} \mathrm{W}\right)$ in

902005 (Sandin et al. 2008) and 2007 and at Palmyra Atoll NWR (5.9 N, 162.1 ${ }^{\circ} \mathrm{W}$ ) in 2010.

91 Kingman and Palmyra are approximately $60 \mathrm{~km}$ apart and are the two northernmost reefs in the

92 Line Islands chain (Fig. 1). Kingman, lacking emergent vegetated dry land, is an atoll reef,

93 whereas Palmyra supports numerous vegetated islets and is a true atoll (hereafter, both are called

94 atolls) (Maragos and Williams 2011). The reefs of Kingman and Palmyra cover approximately 48

$95 \mathrm{~km}^{2}$ and $52 \mathrm{~km}^{2}$, respectively (depth range = $30 \mathrm{~m}$ to shoreline). Neither Kingman nor Palmyra

96 has ever had a permanent resident human population. During WWII-era temporary occupation by

97 the U.S. Navy on Palmyra several alterations were made, including lagoon dredging and

98 causeway construction that altered water flow in and out of the lagoon and shifted patterns of

99 coastal erosion and sedimentation (Collen et al. 2009). Palmyra’s lagoon is now heavily

100 degraded, characterized by high turbidity, sedimentation, and a benthos dominated by sponges,

101 not corals (Knapp et al. 2012) (Fig. 3h). Present-day direct human impacts at Palmyra are

102 minimal to non-existent; only a small team of scientific researchers and staff (4 - 20 people) are

103 resident at the on-island research station.

104 Benthic community surveys

105 Study sites were chosen using a stratified random design within each of the major reef habitats

106 found at Kingman and Palmyra (Fig. 1). Although reef flats are present on both atolls, their

107 shallow and exposed nature made surveying them unsafe, thus no sampling occurred here To test

108 the effect of habitat on benthic community patterns (while keeping depth constant), surveys were 
109 conducted at $10 \mathrm{~m}$ depths across all three reef habitats found at Kingman (patch reef, backreef,

110 and forereef). Reef habitats at Palmyra varied greatly in their depth ranges, confounding any

111 explicit test of habitat. To test the effect of depth (while keeping habitat constant), surveys were

112 conducted at 5, 10 and $20 \mathrm{~m}$ on the forereef at both Kingman and Palmyra. We also tested the

113 effect of depth on the reef terrace at Palmyra by surveying at 5 and 20 m; we did not obtain

114 adequate replication at the $10 \mathrm{~m}$ depth strata $(\mathrm{n}=2)$ to include this information. Finally, we

115 surveyed a unique shallow ( $<3 \mathrm{~m}$ ) backreef habitat in Palmyra’s northeast (Fig. 1). Along each

116 transect, percent cover of benthic organisms was calculated using a modification of the

117 photoquadrat method (Preskitt et al. 2004). At Kingman, two $25 \mathrm{~m}$ transects (separated by $10 \mathrm{~m}$ )

118 were placed on the benthos at each depth at each site, while at Palmyra a single $50 \mathrm{~m}$ transect

119 was used. At Kingman, 10 photoquadrats were captured adjacent to the transect line at fixed

120 intervals, totaling 20 photoquadrats per site. At Palmyra, the number varied spatially but

121 generally equaled $10-20$ photoquadrats at fixed intervals along each transect (Suppl. Table 1).

122 Each photograph captured an area of $0.54 \mathrm{~m}^{2}$ in 2005 and $0.63 \mathrm{~m}^{2}$ in 2007 and 2010. Image

123 analysis was completed using Photogrid 1.0. One hundred points were placed over each

124 photograph in a stratified random design. Organisms under each point were identified to the

125 genus level, with some categories later combined in order to standardize suspected variations in

126 taxonomic identification (e.g., the zooxanthellate soft corals Cladiella, Lobophytum, and

127 Sinularia were combined into "leather coral”). Turf algae (including the "epilithic algal matrix")

128 were defined as a mixed community of filamentous algae and cyanobacteria generally less than

$1292 \mathrm{~cm}$ tall. Crustose coralline algae (CCA; multiple genera) were identified to functional group.

130 Calcified macroalgae were separated from fleshy macroalgae by the presence of calcium

131 carbonate $\left(\mathrm{CaCO}_{3}\right)$; all taxa that contained $\mathrm{CaCO}_{3}$ were considered calcified (these were 
132 principally species of Halimeda and Peyssonnelia). All benthic organisms that produce calcium

133 carbonate were combined to define total calcified cover. Raw percent cover data for all habitats

134 and depth strata are reported in Supplementary Table 1.

\section{Wave energy}

136 We consider the effects of wave energy by comparing spatial patterns of benthic communities 137 across horizontal gradients in wave power, calculated as:

$$
\frac{\rho g^{2}}{64 \pi} H_{s}^{2} T_{p}
$$

139 where $\rho$ is the density of seawater $\left(1024 \mathrm{~kg} \mathrm{~m}^{-3}\right), \quad g$ is the acceleration of gravity $\left(9.8 \mathrm{~m} \mathrm{~s}^{-2}\right)$,

$140 H_{s}$ is mean significant wave height (m), and $T_{p}$ is the dominant wave period (s). To quantify wave

141 energy (kW/m), we used NOAA’s Wave Watch III (WWIII; http://polar.ncep.noaa.gov/waves); a

142 global, full-spectral wave model. A $1^{\circ}$ spatial resolution, $3 \mathrm{hr}$ output of mean significant wave

143 height (average of 1/3 largest wave heights), dominant period (time between two consecutive

144 wave crests or troughs), and direction ( $\mathrm{D}_{p}$; degrees north from which the waves are traveling)

145 from January 1997 - March 2010 was used. Kingman and Palmyra were divided into 16 discrete

$14622.5^{\circ}$ sectors (each $90^{\circ}$ segment subdivided into four). Long-term climatological means in wave

147 energy were calculated by averaging all $3 \mathrm{hr}$ time steps over the entire time series for each sector.

148 Because wave energy standard deviation was highly correlated with the mean ( $r=93.3 \%)$, it was

149 not included as an independent predictor in the analyses. The WWIII model output reflects

150 deep-water wave energy, not a direct measurement of wave stress across different habitats and

151 depths. Because previous research has shown a strong linear relationship between deep-water

152 offshore waves and wave-induced currents on reef-ecosystems (Hearn 1999), this method is a 
153 good first-order approximation of wave forcing on coral reefs. To test for horizontal changes in

154 wave energy, not changes as a direct result of changes in depth or habitat type, we limit

155 comparisons of wave energy to forereef benthic communities at $10 \mathrm{~m}$.

\section{Statistics}

157 Patterns of benthic communities were investigated at three taxonomic resolutions: 1) percent 158 cover of calcified versus non-calcified (fleshy) organisms, 2) percent cover of major functional 159 groups (hard coral, soft coral, CCA, other calcified macroalgae, fleshy macroalgae, other), and 3)

160 percent cover of genera. All analyses were performed using R 2.15.1 (R Development Core

161 Team, http://www.r-project.org) unless otherwise stated. We used a permutational multivariate 162 analysis of variance (PERMANOVA) (Anderson 2001) using the adonis function (vegan 163 package) to test the effect of reef habitat and depth, and all subsequent pairwise comparisons 164 within each factor. Results of each PERMANOVA were visualized with a canonical analysis of 165 principal coordinates (CAP) based on a discriminant analysis (Anderson and Willis 2003) using 166 the CAPdiscrim function (BiodiversityR package). Individual variables that might be responsible

167 for any group differences in the CAP analysis were investigated by calculating Spearman's Rank 168 correlations of the canonical ordination axes with the original variables. Variables with strong 169 correlations (in this study, $\geq 0.4$ ) were identified as "indicator genera" (i.e., driving group 170 separation in multivariate space). Indicator genera need not be the most dominant (i.e. the

171 organisms with the highest overall percent cover), but instead are those organisms contributing

172 most to within-group similarity, while simultaneously contributing most to between-group

173 dissimilarity. We provide the "allocation success" results for each CAP analysis in

174 Supplementary Table 2. Allocation success (expressed as a percentage) gives a measure of how 175 distinct a group is relative to all other groups (with group defined as a level within a factor; e.g., 
176 the level forereef within the factor reef habitat). Allocation success indicated a more distinct

177 group than expected by chance alone when values exceeded $100 / n$, with $n$ being the number of $a$

178 priori defined groups. All PERMANOVA and CAP analyses were based on 10,000 random

179 permutations of the raw data.

180 To quantify the proportion of variation in benthic communities explained by horizontal gradients

181 in wave energy, we used a permutational distance-based multivariate linear model (McArdle and

182 Anderson 2001) using the Fortran program DisTLM_foward (Anderson 2003). To better explore

183 the relationships between benthic communities and wave energy on the forereef at each atoll, we

184 calculated univariate regression models for major functional groups and individual indicator

185 genera that dominated the benthos. These univariate models should be considered more like data

186 exploration, unlike the formal hypothesis testing of the multivariate analyses.

187 Finally, the spatial clustering of benthic taxa was calculated using dispersion-based weighting

188 (Clarke et al. 2006), which measures deviations of the response variable (e.g., hard coral cover)

189 from a generalized Poisson distribution using a test by permutation (1000 random permutations

190 of the raw data). This approach is robust to flexible rules of clustering behaviour, as may be

191 exhibited by hard coral communities, and for data not displaying a normal distribution, such as

192 the percent cover data used in this study (Clarke et al. 2006). The clustering measure is given by

193 the D statistic (variance to mean ratio), with higher values representing higher levels of spatial

194 clustering (Clarke et al. 2006). Values of D were determined at the site level, with individual

195 quadrats within any given site acting as the units of replication.

196 Results

197 Reef habitats at Kingman and Palmyra 
198 Kingman's lagoon was generally deep (> $30 \mathrm{~m}$ ) and contained numerous patch reefs $50-200 \mathrm{~m}$

199 in diameter, extending $2-10 \mathrm{~m}$ from the surface (Fig. 2a-d, Fig. 4a). Kingman's backreef slopes

200 were steep ( $30-50^{\circ}$ inclination) and extended beyond $30 \mathrm{~m}$ depth in many places before

201 merging with the lagoon floor (Fig. 2e-f, Fig. 4a). Kingman’s forereefs in the north and south

202 gradually sloped for approximately 30 - $60 \mathrm{~m}$ out from the reef crest before dropping off sharply 203 beyond $20 \mathrm{~m}$ depth (Fig. 2g-h, Fig. 4a).

204 Palmyra's reef habitats included elongated reef terraces in the west and east. The shallow $(<5 \mathrm{~m})$ 205 portion of the western terrace (Fig. 3a-b) merged with lagoon flats to the east and gradually 206 sloped to the west for approximately $4-5 \mathrm{~km}$ before becoming a deeper ( $>20 \mathrm{~m}$ ) sloping terrace 207 habitat (Fig. 3c) and dropping off sharply beyond $30 \mathrm{~m}$ depth (Fig. 4b). In the far east, the 208 shallow terrace habitat was extremely exposed, and quantitative surveys were not possible. 209 Qualitatively, the shallow eastern terrace was dominated by sand, with sparse patches of coral. 210 Within approximately $5 \mathrm{~km}$ east of this sand zone, the eastern terrace reached depths of $20 \mathrm{~m}$ 211 before dropping off sharply beyond $30 \mathrm{~m}$ depth. Forereef habitats along the north and south 212 coasts of Palmyra (Fig. 3d-f) merged with the deeper terrace habitats at their western and eastern 213 extremities. Forereef steepness varied, but generally a sharp dropoff occurred at $30 \mathrm{~m}$ depth (Fig.

214 4c). Shallow ( $<1 \mathrm{~m}$ ) lagoon flats ran along the north and south shores of Palmyra, often merging 215 with the reef crest (Fig. 4c); thus, true backreef habitats were restricted to the northeast (Fig. 1c, 216 Fig. 3g) and were not comparable to Kingman's backreef.

\section{Overall Functional Group Cover}

218 At Kingman, across all reef habitats and depths, mean hard coral cover was $42 \%$, crustose 219 coralline algae (CCA) 22\%, other calcified macroalgae 8\%, soft coral 6\%, fleshy macroalgae 
$220 \quad 0.7 \%$, and turf algae $12 \%$. At Palmyra, excluding the northeast backreef habitat, mean hard coral

221 cover was $29 \%$, CCA $24 \%$, other calcified macroalgae $14 \%$, soft coral $7 \%$, fleshy macroalgae

$2225 \%$, and turf algae 19\%. Mean hard coral cover at Palmyra's northeast backreef was 76\%, the

223 highest of any habitat surveyed at the two atolls (Fig. 4c). The mean cover of calcified organisms

224 (sum of hard coral, CCA, other calcified macroalgae, and other calcified invertebrates) was $74 \%$

225 at Kingman (range $=54-86 \%)$ and 67\% at Palmyra (range $=56-77 \%)($ Suppl. Table 1$)$.

226 Benthic community patterns across reef habitats

227 At Kingman, benthic communities differed across reef habitats at $10 \mathrm{~m}$ at all three taxonomic 228 resolutions (Table 1, Suppl. Table 2). The patch reef and forereef were characterized by a higher 229 cover of calcified organisms, particularly hard coral, than the backreef, which had a higher cover 230 of turf algae (Fig. 4a). At the genus level, the patch reef and backreef were dominated by Porites, 231 which composed $\geq 80 \%$ of the hard coral cover present in both habitats (Table 2). In contrast, on

232 the forereef, the coral communities were more diverse, with a greater number of genera

233 contributing to overall hard coral cover. Acropora and Pocillopora dominated the forereef habitat 234 and together with Porites and Montipora composed $>80 \%$ of the hard coral cover present (Table 235 2).

236 Indicator genera driving separation among Kingman's reef habitats included a range of 237 functional groups (Fig. 5a). On patch reefs, the coral Porites both dominated in percent cover 238 and was the strongest indictor genera of this habitat (Fig. 5a). Other indicator genera on patch 239 reefs were Fungia corals, the giant clam Tridacna, and the fleshy macroalga Avrainvillea (Fig.

240 5a). While the overall cover of Avrainvillea was low (Suppl. Table 1), the rare nature of this alga

241 made it a particularly strong discriminating species between reef habitats. On the backreef, 
242 although Porites was the most dominant coral, it was not a strong indicator distinguishing this

243 habitat. Indicative genera on the backreef were turf algae, sand, the calcifying macroalga

244 Halimeda, and the hard coral Turbinaria (Fig. 5a). Finally, on the forereef, three of the four most

245 abundant corals (Acropora, Pocillopora, and Montipora) were also strong indicator genera for

246 this habitat (Fig. 5a). Other indicator genera on the forereef included the calcifying macroalga

247 Peyssonnelia, the fleshy macroalga Dictyosphaeria, leather corals, and the hard corals Pavona, 248 Montastrea, Lobophyllia, Favites, and Hydnophora (Fig. 5a).

249 Benthic community patterns across depths

250 At Kingman, benthic communities differed across forereef depths, particularly at the functional 251 group and genus level (Table 1, Suppl. Table 2). Hard coral cover peaked at mid depths (10 m), 252 CCA decreased with depth, other calcifying macroalgae increased with depth, and soft coral and 253 turf algae peaked at deeper (20 m) depths (Fig. 4a). At 5 and 10 m, Acropora and Pocillopora 254 dominated, representing $>50 \%$ of hard coral cover at these depths (Table 2). At $20 \mathrm{~m}$, Porites 255 and Favia were the dominant corals (Table 2).

256 Indicator taxa driving separation among forereef depths on Kingman included a range of 257 functional groups (Fig. 5b). In addition to high CCA cover, shallow depths were characterized by 258 the giant clam Tridacna, the hard coral Pavona, and the hydrozoan fire coral Millepora. The 259 corals Acropora and Pocillopora both had high percent cover values at these depths, and together 260 with Montipora, were strong indicators for shallow and mid-depths (Fig. 5b). At $20 \mathrm{~m}$, the 261 increase in calcified macroalgae cover was strongly driven by Halimeda, and the increase in soft 262 coral cover was driven by leather corals and Pachyclavularia/Stereonephthya (Fig. 5b). Turf 263 algae were also characteristic of the $20 \mathrm{~m}$ depth strata. Characteristic hard corals at $20 \mathrm{~m}$, in 
264 addition to the two most abundant (Porites and Favia), were Fungia, Lobophyllia, Platygyra, 265 and Herpolitha (Fig. 5b).

266 On Palmyra's reef terrace, benthic communities differed between shallow and deeper depths

267 (Table 1, Suppl. Table 2). Hard coral, CCA, and fleshy macroalgae (particularly Lobophora)

268 characterized the shallows, while soft corals and other calcified macroalgae, particularly

269 Peyssonnelia, were indicative of deeper depths (Fig. 4b, Suppl. Table 1). At 5 m, Montipora

270 dominated and represented $71 \%$ of the hard coral cover present. Montipora and Acropora

271 together composed $>80 \%$ of the hard coral cover on the shallow terrace (Table 3). At $20 \mathrm{~m}$,

272 Porites dominated and represented $67 \%$ of the hard coral cover present. In conjunction with

273 Pocillopora and Turbinaria, these three genera composed $>80 \%$ of the hard coral cover present

274 on Palmyra’s deep terrace (Table 3).

275 On Palmyra's forereef, the overall cover of calcified and non-calcified organisms did not vary

276 across depths (Table 1), but the communities comprising each of the two groups changed. Hard

277 coral and turf algae cover was similar across depths and the cover of fleshy macroalgae peaked

278 in the shallows. CCA cover progressively decreased with depth, while the cover of other

279 calcified macroalgae (particularly Peyssonnelia) and soft corals increased with depth (Fig. 4c).

280 The hard coral community was generally dominated by Pocillopora and Porites, which together

281 with Montipora and Pavona composed $>50 \%$ of the hard coral cover at each forereef depth

282 (Table 3). The hard coral community on the forereef was more diverse than on the reef terrace,

283 with six to seven genera comprising $80 \%$ of the hard coral cover across forereef depths (Table 3).

284 The hard corals Pocillopora and Montastrea, together with the fleshy macroalgae Caulerpa and

285 Lobophora, were indicative of shallow to mid depths, with Lobophora particularly indicative of 
286 shallow depths (Fig. 5c). The most abundant hard corals at $20 \mathrm{~m}$ (Porites, Pocillopora, and

287 Pavona) were not strong indicators for this deeper depth. Instead, the hard corals Psammocora

288 and Leptoseris, and corals within the family Fungiidae (Fungia, Herpolitha, and Halomitra),

289 were characteristic of 20-m depths on Palmyra’s forereef (Fig. 5c).

290 Horizontal Wave Energy Gradients

291 Kingman and Palmyra experience similar wave forcing conditions, with high wave energy (40 $29260 \mathrm{~kW} / \mathrm{m})$ from the north and northwest $\left(292.5-360^{\circ}\right)$; moderate energy $(20-30 \mathrm{~kW} / \mathrm{m})$ from 293 the south, west, and northeast $\left(180-292.5^{\circ}\right.$ and $\left.0-90^{\circ}\right)$; and low energy $(<20 \mathrm{~kW} / \mathrm{m})$ from the 294 southeast $\left(90-157.5^{\circ}\right)($ Fig. 6 A). Over the $13+$ year data record, $62 \%$ of all incident waves were 295 within the $45-90^{\circ}$ sectors (largest sector value of 32.1\%; Fig. 6B). Waves from the north and 296 northwest accounted for $18 \%$ of all incoming waves (largest sector value of $12.2 \%$ ), while all 297 other sectors accounted for $<20 \%$ (largest sector value of $6.3 \%$ ).

298 At $10 \mathrm{~m}$ on Kingman's forereef, horizontal gradients in wave energy explained 51\% of the 299 variation in percent cover of calcified versus non-calcified organisms (distlm, Pseudo-F = $30013.484, \mathrm{P}=0.0073$ ). Percent cover of calcified organisms decreased as wave energy increased, 301 with an approximately 20\% drop in cover with a doubling of wave energy (Fig. 7a). In contrast, 302 cover of non-calcified organisms increased approximately threefold with a doubling of wave 303 energy (Fig. 7a). At the functional group level, $48 \%$ of the variation in benthic community cover 304 was explained by variation in wave energy (distlm, Pseudo-F $=12.020, \mathrm{P}=0.0007$ ). Hard coral 305 cover decreased from approximately $60 \%$ to $20 \%$ with a doubling in wave energy (Fig. $7 \mathrm{~b}$ ); this 306 appeared to be driving the negative relationship between calcified cover and wave energy. In 307 contrast, turf cover increased approximately threefold with a doubling in wave energy (Fig. 7b); 
308 this appeared to be driving the positive relationship between non-calcified cover and wave

309 energy. Even at the genus level, variations in wave energy explained $40 \%$ of the variation in

310 benthic community cover (distlm, Pseudo-F $=8.482, \mathrm{P}=0.0001$ ). Specifically, cover of the hard

311 coral Acropora was negatively related to wave energy, decreasing from approximately $30 \%$ to

312 almost zero with a doubling of wave energy (Fig. 7c). In contrast, although a partially calcified

313 organism, cover of the encrusting red alga Peyssonnelia was positively related to wave energy,

314 doubling with a doubling of wave energy (Fig. 7c). Finally, the spatial clustering of hard coral

315 cover at $10 \mathrm{~m}$ approximately doubled as wave energy doubled (Fig. 7d). No one genus appeared

316 predominantly responsible for this relationship. No other functional groups or genus-level

317 indicator variables showed strong relationships with wave energy.

318 On Palmyra’s forereef at $10 \mathrm{~m}$, there were no significant relationships between horizontal

319 gradients in wave energy and percent cover of calcified versus non-calcified organisms (distlm,

320 Pseudo- $\mathrm{F}=0.2802, \mathrm{P}=0.591$ ), cover of various functional groups (distlm, Pseudo- $\mathrm{F}=1.2121, \mathrm{P}$

$321=0.329$ ), or cover of various genera (distlm, Pseudo- $\mathrm{F}=1.2816, \mathrm{P}=0.237$ ).

\section{Discussion}

323 Benthic communities at Kingman Reef and Palmyra Atoll were dominated by reef-building

324 calcifying organisms, namely hard corals and crustose coralline algae. This is consistent with

325 patterns observed at other remote, often uninhabited, islands in the Pacific, including the U.S.

326 Phoenix Islands (Vroom et al. 2010) and parts of the Northwestern Hawaiian Islands (Vroom and

327 Braun 2010; Page-Albins et al. 2012). In contrast, more impacted reef communities, such as the

328 populated islands of Kiritimati and Tabuaeran that neighbor Kingman and Palmyra, are typically

329 characterized by a higher cover of fleshy turf and macroalgae (Sandin et al. 2008). 
331 At Kingman and Palmyra, although differences in benthic communities were observed among

332 reef habitats, some consistent patterns emerged. Hard coral cover was generally high, and one or

333 two genera heavily dominated in sheltered habitats such as Kingman's patch reefs and Palmyra's

334 shallow reef terrace. The intermediate disturbance hypothesis predicts that, in the absence of

335 frequent disturbance, a climax community emerges that becomes dominated by a small number

336 of competitively superior species (으nell 1978; Rogers 1993). Kingman’s patch reefs were

337 dominated almost exclusively by slow-growing, massive Porites spp. corals, which are not rapid

338 colonists following disturbance events (Glynn 1993). This provides indirect evidence of

339 competitive exclusion and suggests that Kingman's patch reefs represent a low disturbance

340 environment with mature communities at the equilibrium end of the scale within a

341 nonequilibrium system (ughes and Connell 1999). Furthermore, as the establishment of climax

342 communities is often prevented by routine mortality (Tanner et al. 1994), the mortality of these

343 massive Porites must be low enough to maintain a monopolization of space. This type of

344 monospecific dominance in sheltered reef habitats by slow-growing Porites has been noted

345 elsewhere in the Pacific, for example in parts of the Hawaiian Archipelago (Grigg and Maragos

346 1974; Grigg 1983; Page-Albins et al. 2012).Evidence suggests that Palmyra’s shallow reef

347 terrace was once heavily dominated by the branching coral Acropora acuminata (Williams et al.

348 2010), likely as a result of its fast growth rate, its ability to spread via fragmentation, and its

349 ability to shade competitors (Lang and Chornesky 1990). The 1998 mass bleaching event caused

350 high mortality in A. acuminata (Williams et al. 2010), and Palmyra's shallow terrace is now

351 dominated by encrusting Montipora; however, Acropora is the second most abundant coral

352 genus. While Palmyra's shallow terrace has high hard coral cover and relatively low diversity, 
353 this habitat is still unlikely in an equilibrium state. A recent disease outbreak targeting tabular

354 Acropora on Palmyra's shallow reef terrace (Williams et al. 2011a) highlights the dynamic nature

355 of this coral community, with routine mortality seemingly preventing monopolization of space

356 by fast-growing Acropora corals.

357 Kingman's forereef, while having similar hard coral cover to the patch reefs, had a higher

358 diversity of coral genera. Here, fast-growing branching and tabular Acropora and corymbose

359 Pocillopora dominated, not slow-growing massive Porites. The high diversity and abundance of

360 fast-growing corals on Kingman's forereef suggests a nonequilibrium community, probably in an

361 earlier successional state (Hughes and Connell 1999). Oceanic forereef habitats are generally

362 more exposed to physical disturbance events, such as large swells, than more sheltered patch reef

363 habitats (Storlazzi et al. 2005). Frequent disturbance events (relative to the life histories of the

364 local assemblages) on Kingman’s forereef may be keeping benthic communities in earlier

365 successional stages (rigg 1983) and preventing competitive dominance by few species (으nell

366 1978; Rogers 1993).

367 Finally, Kingman's backreef had lower coral cover and higher turf algae cover than both the 368 patch reefs and forereef, but as with the patch reefs, coral cover was heavily dominated by

369 massive Porites. On the backreef, conditions may be stable enough to allow competitive

370 dominance by Porites but unstable enough to prevent high Porites cover from establishing

371 (Hughes and Connell 1999). One possible disturbance mechanism could be the transport of

372 debris, such as live and dead coral fragments, by large swell events from the forereef over the

373 reef crest and onto the backreef slope (pers. obs.). Due to the steepness of Kingman's backreef

374 slope, debris could easily reach a depth of $10 \mathrm{~m}$ and still cause physical disturbance. The opening

375 of space on a more regular basis by debris would help to explain the higher cover of turf algae, a 
376 rapid early colonist of bare space following disturbance (Grigg 1983). It is also likely that

377 grazing from the abundant herbivorous fishes at Kingman (Friedlander et al. 2010) prevents

378 transition of this turf algae toward macroalgal dominance on the backreef.

379 Depth

380 Consistent patterns of benthic community zonation emerged across the three forereef depths at

381 Kingman and Palmyra (5, 10, $20 \mathrm{~m}$ ), and these patterns largely held true between the two depths

382 on Palmyra's reef terrace as well (5, $20 \mathrm{~m})$. With increased depth, the most consistent patterns

383 were: a decrease in crustose coralline algae (CCA) and fleshy macroalgae, an increase in other

384 calcified macroalgae, and an increase in soft coral cover. Patterns of hard coral cover were less

385 consistent, remaining similar across depths on Palmyra's forereef, higher in the shallows than the

386 deeper reef on Palmyra's terrace, and peaking at intermediate depths on Kingman's forereef.

387 A peak in hard coral cover at intermediate depths appears to be a common feature of forereef

388 habitats (Huston 1985). At shallow depths, harsh environmental conditions, such as high

389 oscillatory flow and irradiance, can inhibit coral feeding and cause photo damage (Sebens and

390 Johnson 1991; Brown 1997). Such physical conditions can prevent the establishment of benthic

391 communities with high coral cover (Rogers 1993; Hughes and Connell 1999). Meanwhile, lower

392 irradiance at deeper depths can limit photosynthesis by zooxanthellae, while very low flow can

393 lead to the establishment of boundary layers around the coral surface and inhibit nutrient uptake,

394 thus depressing coral respiration and growth (Patterson et al. 1991). Mid-depths on Kingman's

395 forereef thus may represent an energetic optimum for hard corals, increasing overall cover. At

396 mid-depths, levels of irradiance and water flow may maximize the balance between energy

397 intake and respiration ( $\underline{\text { Sebens 1984) }}$ while providing adequate settlement substrate, such as 
398 CCA, for coral recruitment (Price 2010). This interpretation should be applied cautiously to other

399 locations, however, as not all reef environments share the same patterns of wave energy and 400 irradiance.

401 The increase of soft coral cover with depth on Kingman's and Palmyra's forereefs may reflect 402 the fact that zooxanthellate soft corals rely only moderately on phototrophy to supply their 403 carbon requirements. Soft corals often gain a large proportion of their food via heterotrophy, 404 often more effectively than scleractinian corals (Fabricius and Dommisse 2000). Therefore, for 405 soft corals, proximity to allochthonous particulate food from upwelling (i.e., at increased depths) 406 is likely more beneficial than proximity to higher irradiance (i.e., shallower depths), which is 407 often accompanied by high wave stress. Thus, it is hypothesized that higher soft coral cover at 408 depth at Kingman and Palmyra occurs because of higher food availability. The encrusting nature 409 of CCA and its ability to photoacclimate makes it particularly suited to shallow reef slope 410 environments where there is increased oscillatory flow and irradiance (Sheppard 1980; Bulleri

411 2006). CCA cover decreased with depth on Kingman's forereef and Palmyra's forereef and 412 terrace. This likely reflects a shift from thicker-crusted species in the shallows that are more 413 competitive with other encrusting macroalgae, such as Lobophora and Peyssonnelia, and that are 414 more resistant to high flow and sediment abrasion, to species with thinner crusts at deeper depths 415 (Dethier et al. 1991). The biomass of herbivorous fishes is higher at shallower depths on 416 Kingman's forereef (Friedlander et al. 2010), potentially leading to increased grazing pressure on 417 algal turfs and indirectly promoting and facilitating CCA growth and persistence in the shallows 418 (Smith et al. 2010).

419 In contrast to CCA, percent cover of the calcified macroalgae Halimeda and Peyssonnelia 420 increased with depth. Many genera of calcified macroalgae, such as Halimeda, contain 
421 specialized photosynthetic accessory pigments such as siphonoxanthin and siphonein that allow

422 them to effectively harvest light in deeper environments (Drew 2011). In contrast, due to its

423 upright structure, Halimeda is likely vulnerable to being dislodged by wave action in the

424 shallows (Dethier et al. 1991). Increased abundance of herbivorous fishes in the shallows may

425 also increase grazing there (Friedlander et al. 2010), reducing the cover and changing the

426 composition of algal assemblages. The top-down effects of herbivory on the emergent structure

427 of the algal assemblage are difficult to predict, however, without detailed knowledge of foraging

428 patterns and functional responses (e.g., is herbivory under-, over-, or perfectly compensatory

429 with changes in algal production?) (Gruner et al. 2008). The increase of Halimeda and

430 Peyssonnelia with depth could also reflect increased supply of nutrient-rich water from

431 upwelling or internal tides/waves, promoting growth (Smith et al. 2004), as well as competitive

432 release from CCA (Dethier et al. 1991). CCA abundance may be independent of nutrient supply

433 (Belliveau and Paul 2002) or more dependent on high flux rates to reduce boundary layer

434 thickness and ensure that nutrients actually reach the thallus surface.

435 Kingman had virtually no fleshy macroalgae at any depth. The cover of the most dominant fleshy

436 macroalga at Palmyra, Lobophora, was highest in the shallows, likely due to its low-lying,

437 fan-like morphology, affording it protection from high oscillatory flow. The different

438 relationships of macroalgal taxa with depth emphasize the importance of discriminating between

439 calcified and fleshy macroalgae when linking macroalgal cover to environmental conditions on

440 coral reefs.

441 Wave Energy 
442 Forereef benthic community organization at $10 \mathrm{~m}$ depths at Kingman was consistent with

443 predictions of a simple univariate model of wave energy, such that the cover of more

444 wave-tolerant organisms increased with increased wave energy. This was not true for Palmyra,

445 where wave energy showed no clear patterns with benthic community organization.

446 On Kingman’s forereef, the negative relationship between hard coral cover, particularly

447 Acropora, and wave energy at shallow and mid-depths is most likely due to physical disturbance

448 by wave action. The dominant Acropora morphologies on Kingman's forereef are branching and

449 tabular (Kenyon et al. 2010), both of which have high colony shape factors and are thus

450 vulnerable to being dislodged from the substrate or damaged from waterborne projectiles (Madin

$4512005)$. In a community dominated by acroporid corals, then, it follows that increased wave

452 energy results in decreased overall hard coral cover. In contrast, cover of turf algae and the

453 calcified encrusting red alga Peyssonnelia both increased with increased wave energy. Following

454 an inhibition model of succession (Connell and Slatyer 1977), these low-lying, wave-tolerant

455 organisms may become competitively superior under high wave energy conditions (Page-Albins

456 et al. 2012). Alternatively, the higher cover of these fast-growing, early successional organisms

457 could reflect a community continually re-set to an earlier successional state by repeated physical

458 disturbances (Rogers 1993; Hughes and Connell 1999). Analyses of time-series data from

459 permanent plots would be required to discern which of these mechanisms is predominantly

460 producing the observed benthic community patterns.

461 There may be several reasons why wave energy related strongly to mid-depth forereef benthic

462 communities at Kingman but not at Palmyra, two reefs only $60 \mathrm{~km}$ apart that experience similar

463 wave energy climatologies. First, Kingman is dominated by fast-growing, fragile morphologies

464 of Acropora corals, while Palmyra is dominated by fast-growing corymbose Pocillopora corals 
465 and slow-growing massive Porites, both of which are generally more wave-tolerant than

466 Acropora. Second, in a previous study at Palmyra, sedimentation (importantly, the percentage of

467 very fine sediment) was strongly related to overall hard coral cover and genus-level benthic

468 community patterns (Williams et al. 2011b). The degraded lagoon at Palmyra contains high

469 levels of fine sediment that is occasionally transported across the reef during the change in tidal

470 state (pers. obs.). The reef sites most impacted by sedimentation are associated with lower hard

471 coral cover (Williams et al. 2011b) and a higher prevalence of coral bleaching during thermal

472 stress events (Williams et al. 2010). This strong relationship between sedimentation and benthic

473 communities at Palmyra may thus be obscuring any easily detectable signal of wave energy on

474 community organization. Finally, waves can be highly complex due to refraction, dissipation and

475 other wave-bathymetry interactions. The use of deep water wave information in discrete sectors

476 may underrepresent the spatial complexity of nearshore wave forcing, potentially contributing to

477 the observed decoupling of wave energy and benthic community composition around Palmyra.

478 We have not accounted for other physical oceanographic forcings that may be pertinent to

479 benthic reef communities, such as internal tides and patterns of lagoon outflow. A nearshore

480 hydrodynamic model would presumably capture additional physical forcings and therefore be a

481 more appropriate tool for exploring biophysical coupling at Palmyra.

482 Kingman Reef and Palmyra Atoll provide an opportunity to study benthic dynamics and

483 biophysical coupling where calcifying organisms, such as hard corals and CCA, dominate the

484 benthos, where local human impacts are absent, and where the remote oceanic nature of these

485 reef systems provides unique biophysical settings. Elucidating the driving forces of ecological

486 dynamics for such systems will allow discrepancies with more impacted reefs in similar

487 oceanographic settings to be deciphered. Such information should provide a context specific 
488

489

490

491

492

493

494

495

496

497

498

PARC publication number TBD.

Acknowledgements All activities at Kingman Reef and Palmyra Atoll were conducted under the

U.S. Fish and Wildlife Service special use permits 12533-07021 and 12533-10010. We

additionally thank the U.S. Fish and Wildlife Service and The Nature Conservancy for logistical

support. We thank Rachel Morrison, Franklin Viola, Zafer Kizilkaya, Lisa Wedding, and Nichole

Price for contributions to the manuscript. Finally, we thank Peter Vroom, Abel Valdivia and a

third anonymous reviewer for comments that greatly improved this manuscript. SIO is a member

of the Palmyra Atoll Research Consortium (PARC) and the Reefs Tomorrow Initiative. This is

499

500

\section{References}

501

Anderson MJ (2001) A new method for non-parametric multivariate analysis of variance. Austral

502

503

504

505

506

507

508

509

510

511

512

513

514

515

516

517

Anderson MJ (2003) DISTLM forward: a FORTRAN computer program to calculate a distance-based multivariate analysis for a linear model using forward selection. Department of Statistics, University of Auckland, New Zealand.

Anderson MJ, Willis TJ (2003) Canonical analysis of principal coordinates: A useful method of constrained ordination for ecology. Ecology 84:511-525

Barott K, Williams GJ, Vermeij M, Harris J, Smith JE, Rohwer F, Sandin SA (2012) Natural history of coral-algae competition across agradient of human activity in the Line Islands. Mar Ecol Prog Ser 460:1-12

Belliveau SA, Paul VJ (2002) Effects of herbivory and nutrients on the early colonization of crustose coralline and fleshy algae. Mar Ecol Prog Ser 232:105-114

Bradbury RH, Young PC (1981) The effects of a major forcing function, wave energy, on a coral reef ecosystem. Mar Ecol Prog Ser 5:229-241

Brown BE (1997) Coral bleaching: causes and consequences. Coral Reefs 16:129-138

Bulleri F (2006) Duration of overgrowth affects survival of encrusting coralline algae. Mar Ecol Prog Ser 321:79-85 
518

519

520

521

522

523

524

525

526

527

528

529

530

531

532

533

534

535

536

537

538

539

540

541

542

543

544

545

546

547

548

549

550

551

552

553

554

555

556

557

558

559

560

561

562

563
Clarke KR, Chapman MG, Somerfield PJ, Needham HR (2006) Dispersion-based weighting of species counts in assemblage analyses. Mar Ecol Prog Ser 320:11-27

Collen JD, Garton DW, Gardner JPA (2009) Shoreline Changes and Sediment Redistribution at Palmyra Atoll (Equatorial Pacific Ocean): 1874-Present. J Coast Res 25:711-722

Connell JH (1978) Diversity in tropical rain forests and coral reefs. Science 199:1302-1310

Connell JH, Slatyer RO (1977) Mechanisms of succession in natural communities and their role in community stability and organisation. Am Nat 111:1119-1144

Dethier MN, Paull KM, Woodbury MM (1991) Distribution and thickness patterns in subtidal encrusting algae from Washington. Bot Mar 34:201-210

Dollar SJ (1982) Wave stress and coral community structure in Hawaii. Coral Reefs 1:71-81

Dollar SJ, Tribble GW (1993) Recurrent storm disturbance and recovery: a long-term study of coral communities in Hawaii. Coral Reefs 12:223-233

Done T (1983) Coral zonation: its nature and significance. In: Barnes DJ (ed) Perspectives on coral reefs. Australian Institute of Marine Science, Townsville, pp107-147

Drew E (2011) Halimeda. In: Hopley D (ed) Encyclopedia of modern coral reefs. Springer-Verlag, pp535-539

Engelen AH, Berg PA, Olsen JL, Stam WT, Breeman AM (2005) Effects of wave exposure and depth on biomass, density and fertility of the fucoid seaweed Sargassum polyceratium (Phaeophyta, Sargassaceae). J Phycol 40:149-158

Fabricius KE (2005) Effects of terrestrial runoff on the ecology of corals and coral reefs: review and synthesis. Mar Pollut Bull 50:125-146

Fabricius KE, Dommisse M (2000) Depletion of suspended particulate matter over coastal reef communities dominated by zooxanthellate soft corals. Mar Ecol Prog Ser 196:157-167

Friedlander AM, Sandin SA, DeMartini EE, Sala E (2010) Spatial patterns of the structure of reef fish assemblages at a pristine atoll in the central Pacific. Mar Ecol Prog Ser 410:219-231

Glynn PW (1993) Coral reef bleaching: ecological perspectives. Coral Reefs 12:1-17

Grigg RW (1983) Community structure, succession, and development of coral reefs in Hawaii. Mar Ecol Prog Ser 11:1-14

Grigg RW (1995) Coral reefs in an urban embayment in Hawaii: A complex case history controlled by natural and anthropogenic stress. Coral Reefs 14:253-266

Grigg RW, Maragos JE (1974) Recolonization of hermatypic corals on submerged lava flows in Hawaii. Ecology 55:387-395

Gruner DS, Smith JE, Seabloom EW, Sandin SA, Ngai JT, Hillebrand H, Harpole S, Elser J, Cleland EE, Bracken MES, Borer ET, Bolker BM (2008) A cross-system synthesis of consumer and nutrient resource control on producer biomass. Ecol Lett 11:740-755

Hearn CJ (1999) Wave-breaking hydrodynamics within coral reef systems and the effect of changing relative sea level. J Geophys Res (C Oceans) 104:30007-30019

Hughes TP (1989) Community structure and diversity of coral reefs: the role of history. Ecology 70:275-279

Hughes TP, Connell JH (1999) Multiple stressors on coral reefs: a long-term perspective. Limnol Oceanogr 44:932-940

Huston MA (1985) Patterns of species diversity on coral reefs. Annu Rev Ecol Syst 16:149-177

Jackson JBC, Kirby MX, Berger WH, Bjorndal KA, Botsford LW, Bourque BJ, Bradbury RH, Cooke R, Erlandson J, Estes JA, Hughes TP, Kidwell S, Lange CB, Lenihan HS, Pandolfi JM, Peterson CH, Steneck RS, Tegner MJ, Warner RR (2001) Historical Overfishing and the Recent Collapse of Coastal Ecosystems. Science 293:629-637 
564

565

566

567

568

569

570

571

572

573

574

575

576

577

578

579

580

581

582

583

584

585

586

587

588

589

590

591

592

593

594

595

596

597

598

599

600

601

602

603

604

605

606

607

608

Kenyon J, Maragos JE, Vroom P (2012) Monitoring supports establishment of Pacific Remote Islands Marine National Monument. Proceedings of the 12th International Coral Reef Symposium, Cainrs, Australia, 9-13 July 2012 18F

Kenyon JC, Maragos JE, Wilkinson CB (2010) Characterization of coral communities at Kingman Reef in the remote central Pacific Ocean. Atoll Res Bull 584:1-29

Knapp IS, Williams GJ, Carballo JL, Cruz-Barraza JA, Gardner JPA, Bell JJ (2012) Restriction of sponges to an atoll lagoon as a result of reduced environmental quality. Mar Pollut Bull In Press

Lang JC, Chornesky EA (1990) Competition between scleractinian reef corals - a review of the mechanism and effects. In: Dubinsky Z (ed) Coral reefs Ecosystems of the world. Elsevier, pp209-252

Leichter JJ, Salvatore J (2006) Intermittent upwelling and subsidized growth of the scleractinian coral Madracis mirabilis on the deep fore-reef slope of Discovery Bay, Jamaica. Mar Ecol Prog Ser 316:95-103

Madin JS (2005) Mechanical limitations of reef corals during hydrodynamic disturbances. Coral Reefs 24:630-635

Madin JS, Connolly SR (2006) Ecological consequences of major hydrodynamic disturbances on coral reefs. Nature 444:477-480

Maragos JE, Williams GJ (2011) Pacific coral reefs: an introduction. In: Hopley D (ed) Encyclopedia of modern coral reefs. Springer-Verlag,

McArdle BH, Anderson MJ (2001) Fitting multivariate models to community data: A comment on distance-based redundancy analysis. Ecology 82:290-297

McCook LJ (1999) Macroalgae, nutrients and phase shifts on coral reefs: scientific issues and management consequences for the Great Barrier Reef. Coral Reefs 18:357-367

Muscatine L, Porter JW (1977) Reef corals: mutualistic symbioses adapted to nutrient-poor environments. Bioscience 27:454-460

Page-Albins KN, Vroom PS, Hoeke R, Albins MA, Smith CM (2012) Patterns in Benthic Coral Reef Communities at Pearl and Hermes Atoll along a Wave-Exposure Gradient. Pac Sci 66:481-496

Patterson MR, Sebens KP, Olson RR (1991) In situ measurements of flow effects on primary production and dark respiration in reef corals Limnol Oceanogr 36:936-948

Preskitt L, Vroom P, Smith C (2004) A rapid ecological assesment (REA) quantitative survey method for benthic algae using photo quadrats with SCUBA. Pac Sci 58:201-209

Price N (2010) Habitat selection, facilitation, and biotic settlement cues affect distribution and performance of coral recruits in French Polynesia. Oecologia 163:747-758

Rogers CS (1993) Hurricanes and coral reefs: the intermediate disturbance hypothesis revisited. Coral Reefs 12:127-137

Sandin SA, Smith JE, DeMartini EE, Dinsdale EA, Donner SD, Friedlander AM, Konotchick T, Malay M, Maragos JE, Obura D, Pantos O, Paulay G, Richie M, Rohwer F, Schroeder RE, Walsh S, Jackson JBC, Knowlton N, Sala E (2008) Baselines and degradation of coral reefs in the northern Line Islands. PLoS One 3:e1548

Sebens KP (1984) Water flow and coral colony size: Interhabitat comparisons of the octocoral Alcyonium siderium. Proc Natl Acad Sci U S A 81:5473-5477

Sebens KP, Johnson AS (1991) Effects of water movement on prey capture and distribution of reef corals. Hydrobiologia 226:91-101 
609

610

611

612

613

614

615

616

617

618

619

620

621

622

623

624

625

626

627

628

629

630

631

632

633

634

635

636

637

638

639

640

641

642

643

644

645 Figure legends

Sheppard CRC (1980) Coral cover, zonation and diversity on reef slopes of Chagos Atolls, and population structures of the major species. Marine Ecology-Progress Series 2:193-205

Smith JE, Hunter CL, Smith CM (2010) The effects of top-down versus bottom-up control on benthic coral reef community structure. Oecologia 163:497-507

Smith JE, Smith CM, Vroom P, Beach KL, Miller S (2004) Nutrient and growth dynamics of Halimeda tuna on Conch Reef, Florida Keys: Possible influence of internal tides on nutrient status and physiology. Limnol Oceanogr 49:1923-1936

Storlazzi CD, Brown EK, Field ME, Rodgers K, Jokiel PL (2005) A model for wave control on coral breakage and species distribution in the Hawaiian Islands. Coral Reefs 24:43-55

Tanner JE, Hughes TP, Connell JH (1994) Species coexistance, keystone species, and succession: a sensitivity analysis. Ecology 75:2204-2219

Tsuda RT, Fisher JR, Vroom P (2012) Floristic Account of the Marine Benthic Algae from Jarvis Island and Kingman Reef, Line Islands, Central Pacific. Micronesica 43:14-50

Vroom PS, Braun CL (2010) Benthic composition of a healthy subtropical reef: baseline species-level cover, with an emphasis on algae, in the Northwestern Hawaiian Islands. PloS One 5:e9733

Vroom PS, Musburger CA, Cooper SW, Maragos JE, Page-Albins KN, Timmers MAV (2010) Marine biological community baselines in unimpacted tropical ecosystems: spatial and temporal analysis of reefs at Howland and Baker Islands. Biodivers Conserv 19:797-812

Williams GJ, Knapp IS, Maragos JE, Davy SK (2010) Modeling patterns of coral bleaching at a remote Central Pacific atoll. Mar Pollut Bull 60:1467-1476

Williams GJ, Knapp IS, Work TM, Conklin EJ (2011a) Outbreak of Acropora white syndrome following a mild bleaching event at Palmyra Atoll, Northern Line Islands, Central Pacific. Coral Reefs 30:621

Williams GJ, Knapp IS, Maragos JE, Davy SK (2011b) Proximate environmental drivers of coral communities at Palmyra Atoll: establishing baselines prior to removing a WWII military causeway. Mar Pollut Bull 62:1842-1851

Williams ID, Richards BM, Sandin SA, Baum JK, Schroeder RE, Nadon MO, Zgliczynski B, Craig P, Mcllwain JL, Brainard RE (2011c) Differences in Reef Fish Assemblages between Populated and Remote Reefs Spanning Multiple Archipelagos Across the Central andWestern Pacific. Journal of Marine Biology: Article ID 826234 
646 Fig. 1. Location of Kingman Reef and Palmyra Atoll, northern Line Islands (A) and the

647 distribution of survey sites at Kingman in 2007 (B) and at Palmyra in 2010 (C). 05; indicate sites

648 at Kingman surveyed in 2005. Numbers in parentheses refer to the depths (m) surveyed within

649 each reef habitat.

650 Fig. 2. Reef habitats at Kingman Reef: (A, B) Lagoonal patch reef dominated by massive and 651 branching Porites. The shallow areas $(<5 \mathrm{~m})$ of the patch reefs are dominated by mushroom 652 corals (Fungia) and giant clams (Tridacna) (C, D). The exposed shallow $(<5 \mathrm{~m})(\mathrm{E})$ and the 653 deeper backreef $(10 \mathrm{~m})(\mathrm{F})$ have a steep slope incline $\left(30-50^{\circ}\right)$. Kingman’s forereef habitat, 654 where plating and branching Acropora corals dominate at $10 \mathrm{~m}(\mathrm{G})$ and massive Porites 655 characterize the deeper depths (H). Photo credits: ES (A-C, E, G, H), JES (D), GJW (F).

656 Fig. 3. Reef habitats at Palmyra Atoll. Palmyra’s shallow $(<5 \mathrm{~m})$ western reef terrace (A-B) 657 gradually slopes to merge with a deep terrace habitat dominated by massive Porites and soft 658 corals at $20 \mathrm{~m}$ (C). Palmyra’s forereef habitats generally have a steep incline and are dominated 659 by corymbose Pocillopora corals and massive Porites (D-F). The only true backreef at Palmyra 660 is located in the northeast $(\mathrm{G})$. This shallow habitat $(<3 \mathrm{~m})$ boasts the highest cover of hard coral 661 on the atoll and is in stark contrast to the heavily degraded lagoon habitat $(\mathrm{H})$. Photo credits:

662 Franklin Viola (A, C, G), GJW (B, H), Zafer Kizilkaya (D-F).

663 Fig. 4. Reef profiles for Kingman and Palmyra showing changes in percent cover of major 664 benthic functional groups for: the transition from the lagoonal patch reef, across the backreef, 665 and across forereef depths at Kingman (A), the transition from the shallow to the deeper reef 666 terrace at Palmyra (B), and across forereef depths and the unique northeast backreef at Palmyra 667 (C). Dominant hard coral genera (two most abundant in terms of percent cover in rank order) are 
668 indicated across habitats and depths in italics. Dashed lines indicate the position and direction of 669 the cross-sectional profile.

670 Fig. 5. Canonical analysis of principal coordinates (CAP) based on a discriminant analysis,

671 showing those benthic genera responsible for separation across reef habitats at Kingman (A) and 672 across forereef depths on Kingman (B) and Palmyra (C). The squared canonical correlation value 673 for the first two ordination axes is shown in parentheses in each case. Vector lines represent 674 Spearman's Rank correlations (threshold set at $\geq 0.4$ ). The length of each vector line is 675 proportional to the strength of the correlation. CCA, crustose coralline algae; Pachy/Stereo, 676 Pachyclavularia/Stereonephthya.

677 Fig. 6. Mean wave power at Kingman and Palmyra in kW/m calculated for 16 discrete sectors, 678 each spanning $22.5^{\circ}$ starting from $0^{\circ}$. Power calculated using significant wave height, dominant 679 period and direction from NOAA's Wave Watch III, a $3 \mathrm{hr}$ interval, $1^{\circ}$ spatial resolution wave 680 model from January 1997 - March 2010 (A). Numbers in italics represent wave energy values in $681 \mathrm{~kW} / \mathrm{m}$. Wave event frequency (B) is the number of wave events (3 hr output values) in each $68222.5^{\circ}$ sector divided by the total number of events over the $13+$ year time period. Values in italics 683 represent the fraction of waves.

684 Fig. 7. Relationship between benthic communities and wave power $(\mathrm{kW} / \mathrm{m})$ on Kingman’s 685 forereef at $10 \mathrm{~m}$.

686

687 


\section{Figure 1}

Fig.1_map

Map of survey sites

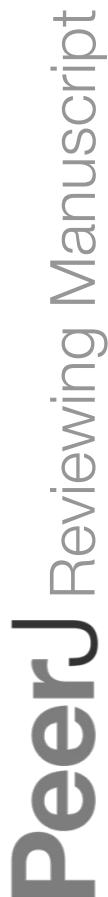

PeerJ reviewing PDF | (v2013:04:416:1:0:NEW 8 May 2013) 


\section{Figure 2}

Fig.2_Kingman habitats

Reef habitats at Kingman Reef 


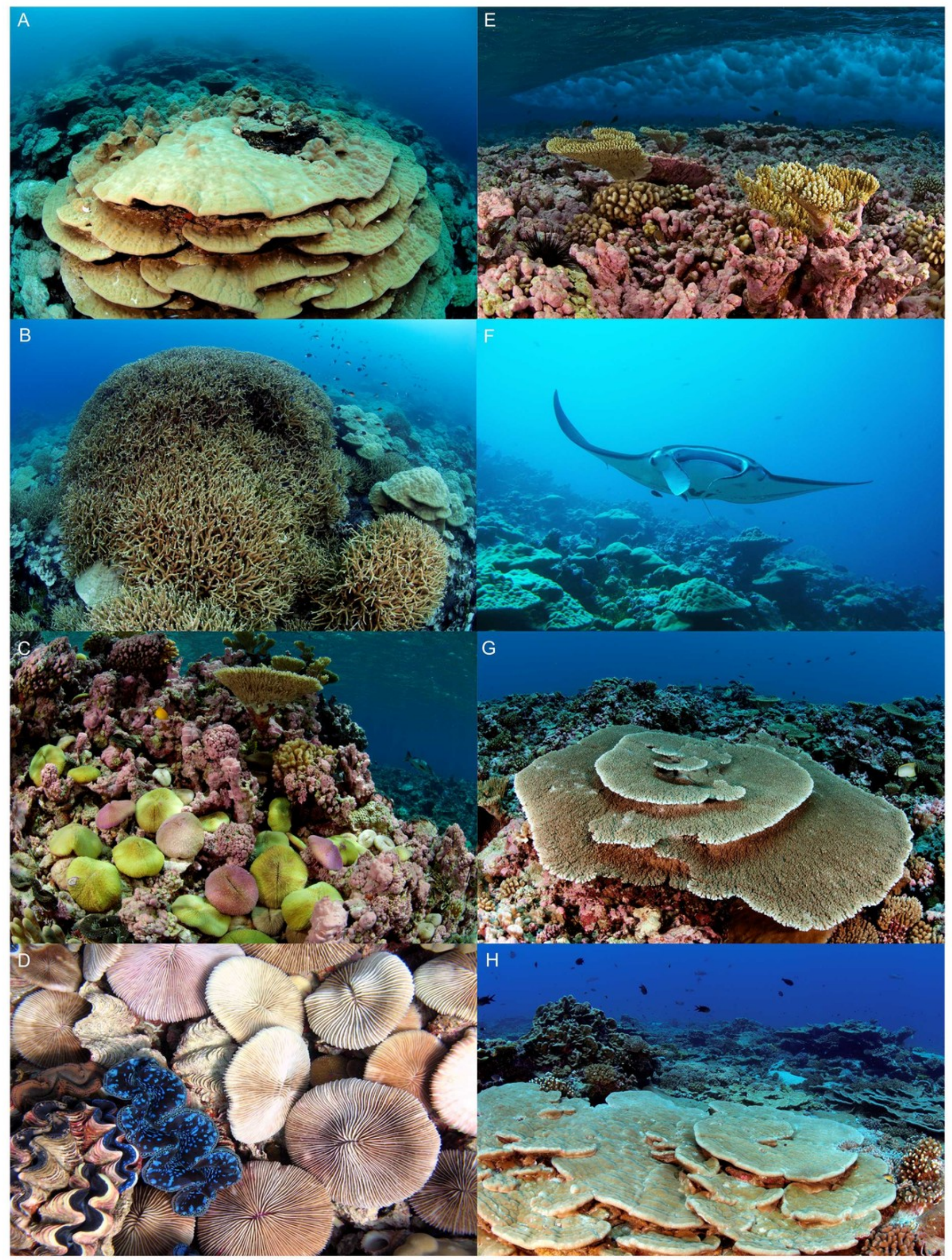




\section{Figure 3}

Fig. 3_Palmyra habitats

Reef habitats at Palmyra Atoll 


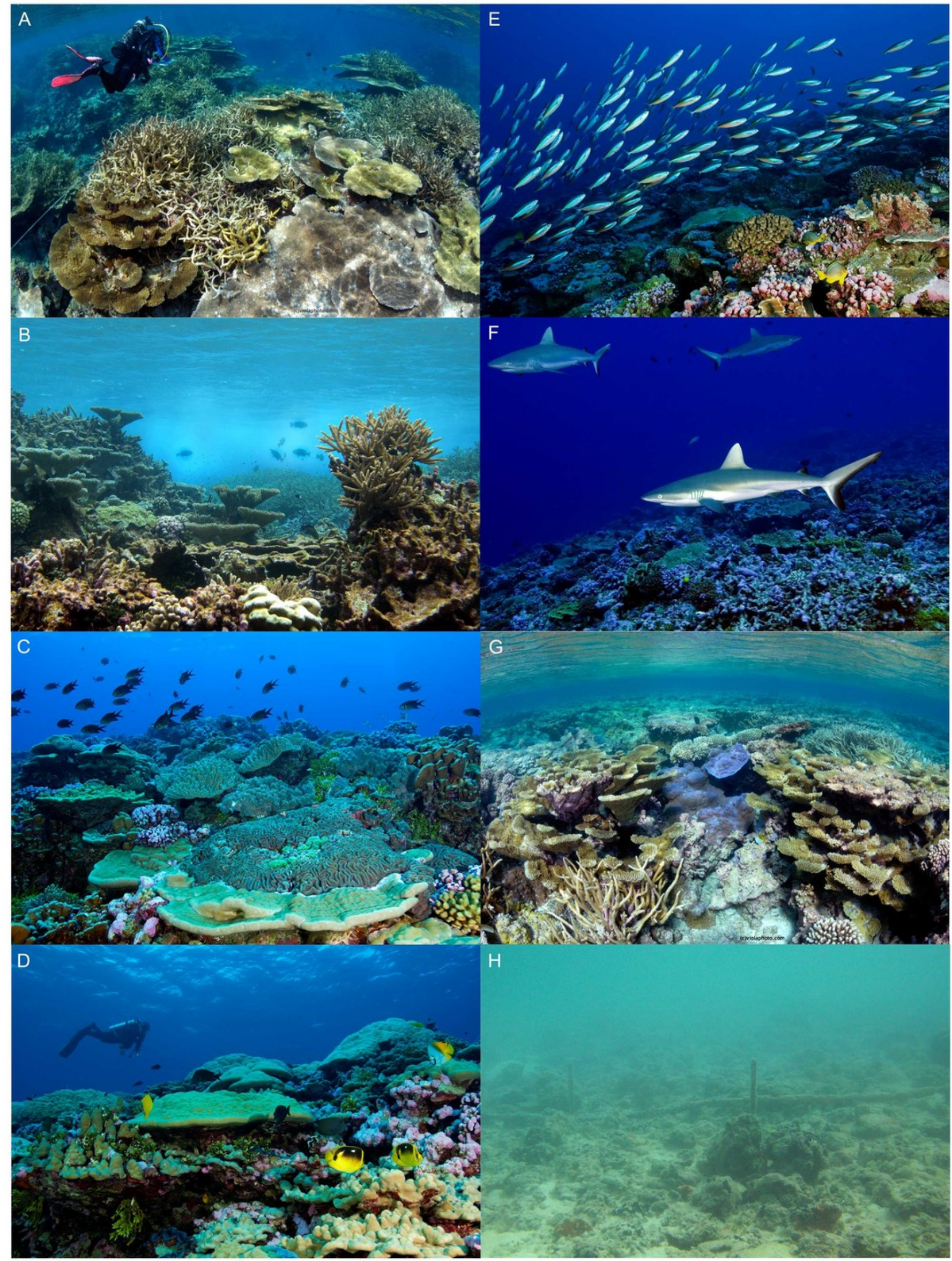




\section{Figure 4}

Fig. 4_reef profiles

Stylized reef profiles from the two islands
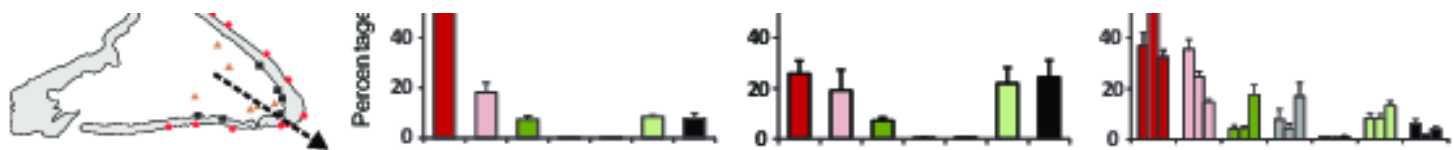

Hard caral

$\square$ CCA

Macraalgae (calcified)

Saftcaral

Macraalgae (flesty)

$\square$ Turf

Other

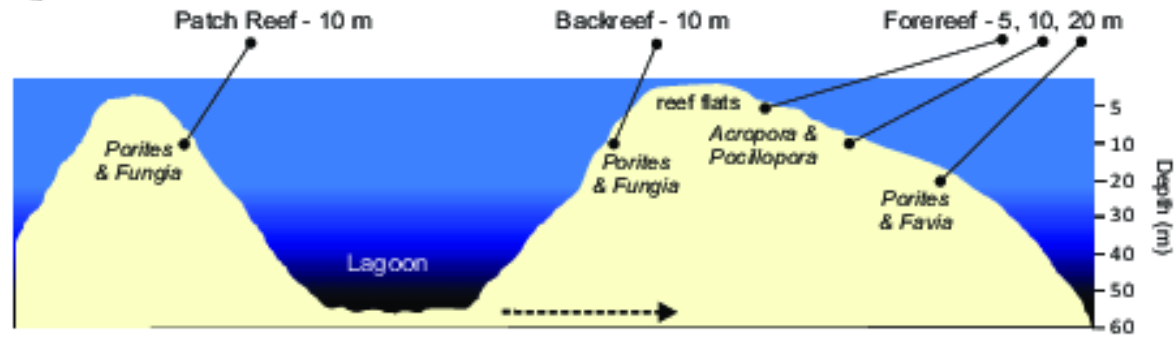

(B) Palmyra Atoll - reef terrace
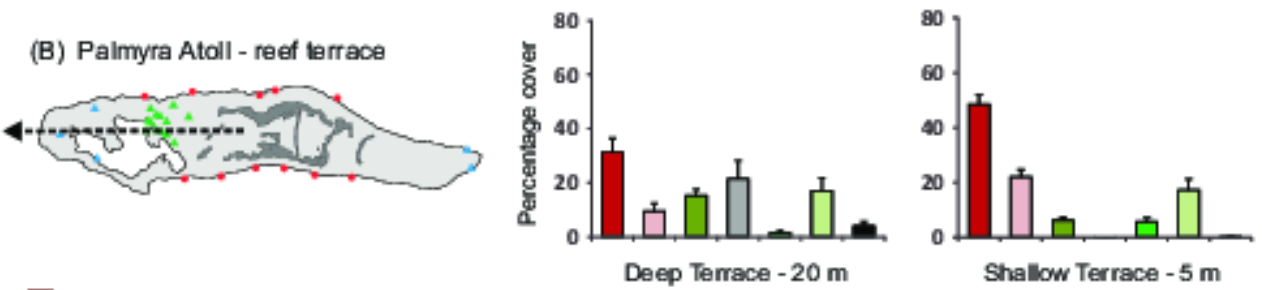

Hard caral

$\square$ CCA

Macraa kase (kaldified)

$\square$ Saft caral

Macras bae pfleshy

$\square$ Turf

Other
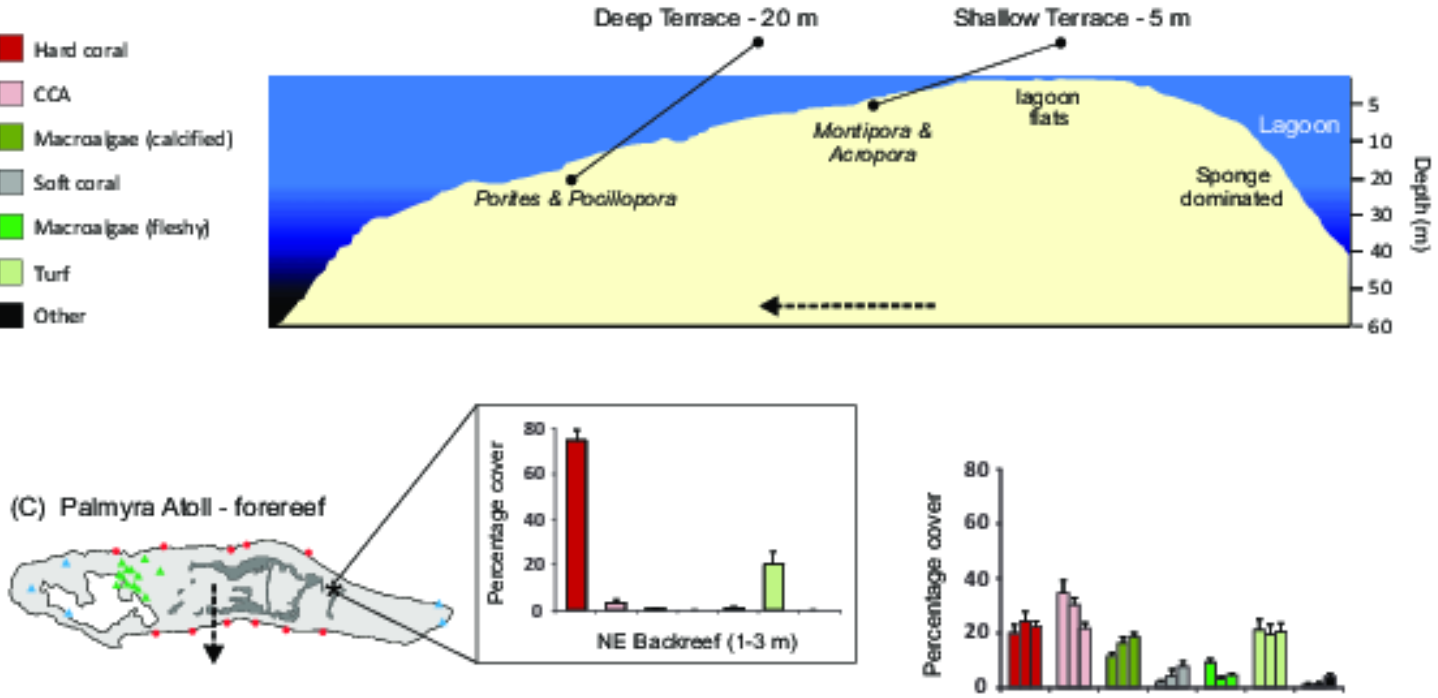

$\square$ Hand caral
$\square$ cCA
$\square$ Macraa gae (calcified)
$\square$ Saft caral
$\square$ Macraa gae pfleshy
$\square$ Turf
Other

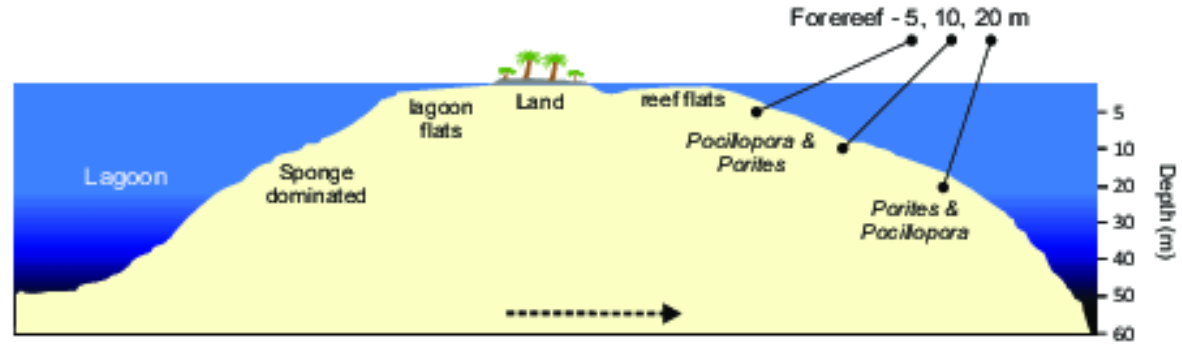




\section{Figure 5}

Fig. 5_CAP plots

Canonical plots

PeerJ reviewing PDF | (v2013:04:416:1:0:NEW 8 May 2013) 

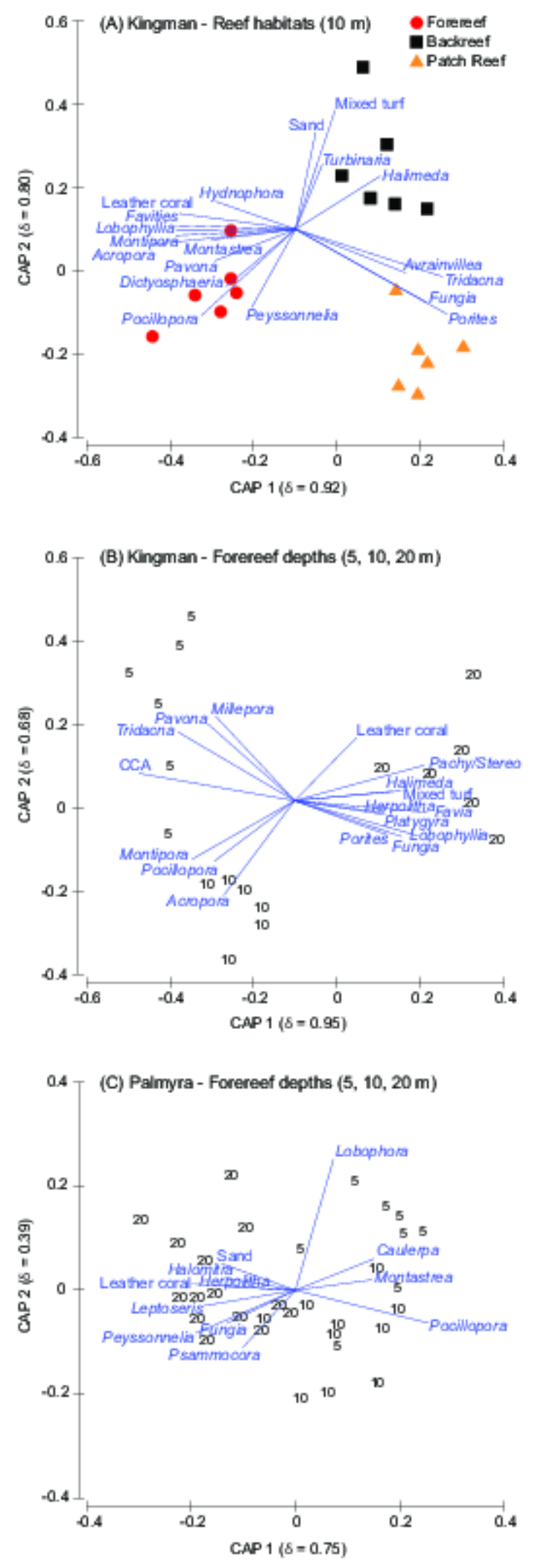


\section{Figure 6}

Fig. 6_wave energy

Wave energy plots for Kingman and Palmyra

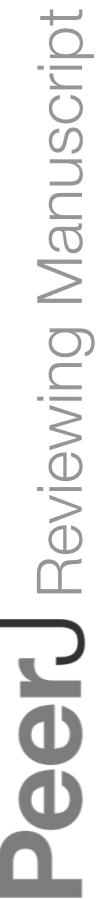

(B) Wave Frequency

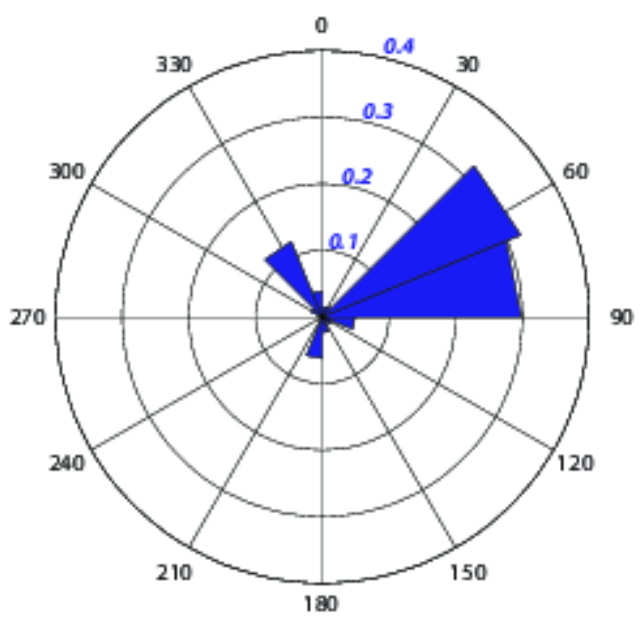




\section{Figure 7}

Fig.7_wave relationships

Relationships between benthos and wave energy

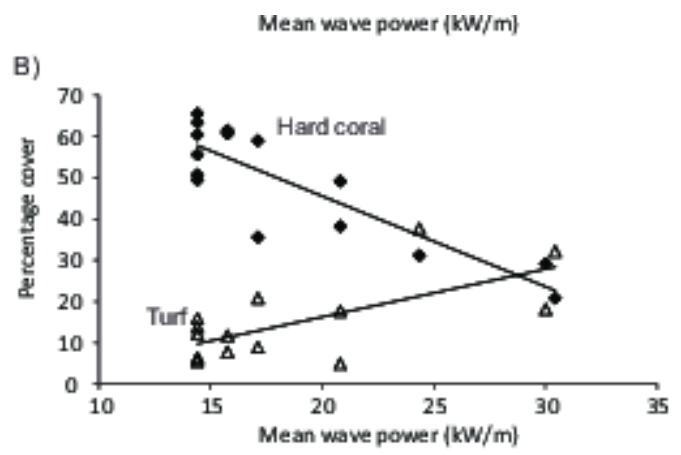

C)
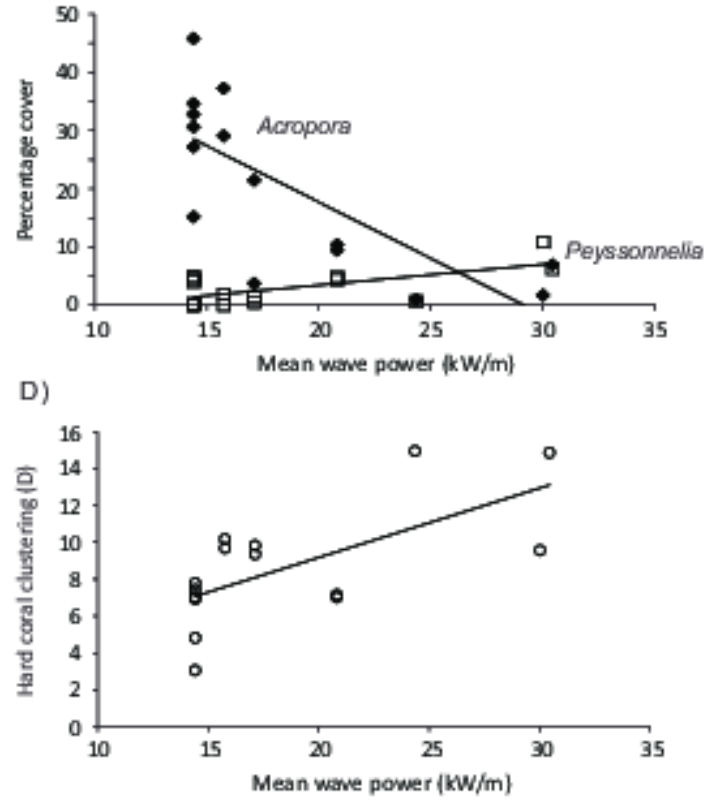


\section{Table $\mathbf{1}_{\text {(on next page) }}$}

Table 1

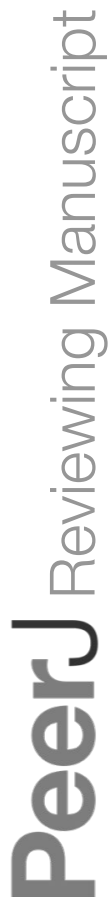


Table 1. Summary statistics of within-island variations in benthic communities at three taxonomic resolutions at Kingman Reef and Palmyra Atoll. (A) Results of permutational analysis of variance analyses; | indicates significant differences between groups in pairwise comparisons; ns, non-significant; NA, pairwise comparison not applicable due to only two groups. Degrees of freedom for each test are shown as subscripts for each respective Pseudo-F value. 


\title{
Table 2 (on next page)
}

\author{
Table 2
}


Table 2. Abundance (mean percent cover) of the top 10 hard corals across reef habitats (patch reef, backreef and forereef) and forereef depths (5, 10, 20 m) at Kingman Reef. The relative contribution of each genus to overall hard coral cover is shown (Rel). Corals in bold make up $\geq 50 \%$ of overall hard coral cover. For complete cover values for all hard coral genera see Supplementary Table 1.

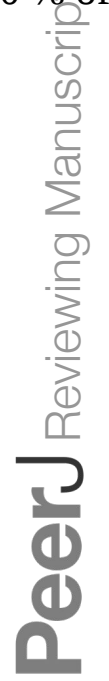




\section{Table 3 (on next page)}

Table 3

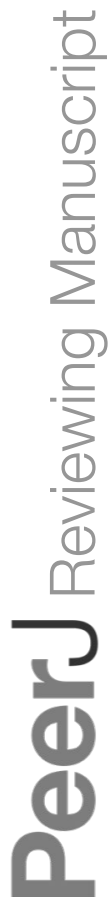


Table 3. Abundance (mean percent cover) of the top 10 hard corals across reef habitats (terrace and forereef) and depths (5, 10, $20 \mathrm{~m}$ ) at Palmyra Atoll. The relative contribution of each genus to overall hard coral cover is shown (Rel). Genera in bold make up $\geq 50 \%$ of overall hard coral gover. For complete cover values for all hard coral genera see Supplementary Table 1.

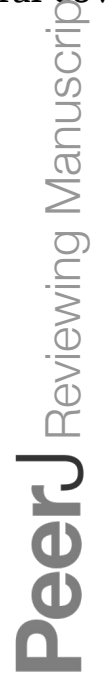

